\title{
ANÁLISE DA PERCEPCC̃̃O AMBIENTAL DOS ALUNOS VISITANTES DO MUSEU DE CIÊNCIAS NATURAIS DO CECLIMAR/IB/UFRGS, IMBÉ (RS)
}

\author{
Vanessa Ochi Agostini ${ }^{1}$ \\ Matias do Nascimento Ritter ${ }^{2}$ \\ Roberto Nascimento de Farias ${ }^{2}$ \\ Ana Carolina Pereira ${ }^{3}$ \\ Luciana Medeiros ${ }^{1}$ \\ Luciana da Silva Menezes ${ }^{2}$ \\ Juliana Fabrício Tisca ${ }^{1}$ \\ Teresinha Guerra ${ }^{2}$
}

\begin{abstract}
RESUMO: O objetivo do presente estudo foi quantificar o grau de percepção ambiental de alunos de diferentes faixas etárias e de diferentes níveis de escolaridade em relação à sua inserção na Natureza. Um questionário estruturado foi aplicado em uma amostra de $20 \%$ do total de alunos visitantes do Museu de Ciências Naturais do CECLIMAR, totalizando 67 questionários. $O$ aumento de respostas positivas, quanto à inserção na Natureza, foi relacionada positivamente ao grau de escolaridade dos entrevistados. Entretanto, não foi possível estabelecer diferenças em relação à percepção ambiental entre o ensino público e o privado. Com o aumento do nível de ensino, a compreensão de que são diversos os modos de inserção à Natureza aumenta, embora a urbanização não seja vista como parte da Natureza.
\end{abstract}

Palavras-chave: Educação Ambiental; Natureza; Questionário Estruturado; Percepção Ambiental.

\footnotetext{
${ }^{1}$ Universidade Federal do Rio Grande (FURG). Programa de Pós-Graduação em Oceanografia Biológica - Instituto de Oceanografia (IO). Avenida Itália Km.8 Campus Carreiros - Caixa Posta 474 - CEP 96201900, Rio Grande, RS.E-mails: nessaochi@gmail.com, lumedeiros.silva@gmail.com, juliana.biologiamarinha@gmail.com.

${ }^{2} U$ niversidade Federal do Rio Grande do Sul, Avenida Bento Gonçalves, 9500/Agronomia, CEP 91501-

970, Porto Alegre, RS, Brasil. E-mails:mnritter@gmail.com, betofarias.bio@gmail.com,

lu.silva.menezes@gmail.com, tg@ecologia.ufrgs.br.

${ }^{3}$ Universidade Federal do Rio Grande do Sul, Departamento de Ecologia. E-mail:

anacarolina.pereira87@gmail.com.
}

Revbea, Rio Grande, V. 8, № 2:93-102, 2013.

revista brasileira 


\section{INTRODUÇÃO}

A Educação Ambiental surgiu para preparar a sociedade para um mundo interdependente e em harmonia com as leis da natureza (PORTO, 1996). A visão medieval defendia a relação íntima entre o homem e o universo. Em contrapartida, a escola cartesiana, proposta pelo francês Réne Descartes, estabeleceu um grande distanciamento na relação homem vs. natureza. A Natureza seria um aparato externo ao ser humano e que serviria para enriquecê-lo materialmente, não sendo mais que um objeto à disposição da razão humana (PELIZZOLI, 2003). Rodrigues e Feijó (2007) verificaram que o antropocentrismo é ainda notório no mundo atual e enfatizam a necessidade de alterar este paradigma. Segundo Fenker (2007), "a ação antrópica é a ação do homem sobre a natureza, de forma a alterar sua condição natural". Brugger (1999) afirma que o conceito de meio ambiente deva incluir a totalidade, como os aspectos naturais e os resultantes das atividades humanas. Portanto, como postulado por Ventura e Sousa (2010): "A relação entre os seres humanos e o ambiente, cerne das discussões sobre a problemática ambiental, deve ser discutida compreendendo a natureza histórica, cultural, biológica e social do ser humano".

O presente trabalho assumiu o termo inserção à natureza como uma congruência dos conceitos de ação antrópica. Discussões com a temática relacionada à problemática ambiental consideram aspectos históricos, sociais, culturais e biológicos intrínsecos da cultura de um povo ou de diferentes grupos. Logo, inserção à natureza reflete o modo como o ser humano contextualiza sua própria relação a ela, seja ela na forma de ação antrópica bem como na forma de se considerar um ser pertencente a ela e não um ser externo que desvincule à ação antrópica.

O objetivo do presente estudo, portanto, foi verificar a percepção ambiental de alunos de diferentes faixas etárias (i.e. diferentes grupos de indivíduos) em relação à inserção na natureza. Especificamente, pretendeu-se constatar a proporção dos estudantes, verificando a influência da idade, do grau de escolaridade e do tipo de ensino (público ou privado) que se consideram inseridos na Natureza. A hipótese é que a idade e o grau de escolaridade têm influência sobre a percepção ambiental, a qual é definida resumidamente como a percepção do ser humano em relação ao ambiente, percebendo de que forma ele se insere ou se relaciona com Natureza. Para isso, considera-se Natureza a biosfera a qual o homem se relaciona.

\section{MATERIAIS E MÉTODOS}

Para testar a veracidade (ou não) da hipótese levantada, um questionário estruturado, em anexo, foi aplicado nos grupos escolares visitantes do Museu de Ciências Naturais do Centro de Estudos Costeiros, Limnológicos e Marinhos (CECLIMAR), em Imbé, RS (Figura 1), entre os meses de abril e maio de 2011, pois estes são os meses de maior intensidade de visitação (RITTER et al., 2009).

Revbea, Rio Grande, V. 8, N²:93-102, 2013. 
No presente trabalho, o universo amostral é desconhecido, ou seja, não há como prever o número de visitantes, ao contrário da maioria dos estudos com Percepção Ambiental em que o número amostral é categórico e delineado antes de sua realização (e.g. PALMA, 2005; BERGMANN, 2007).

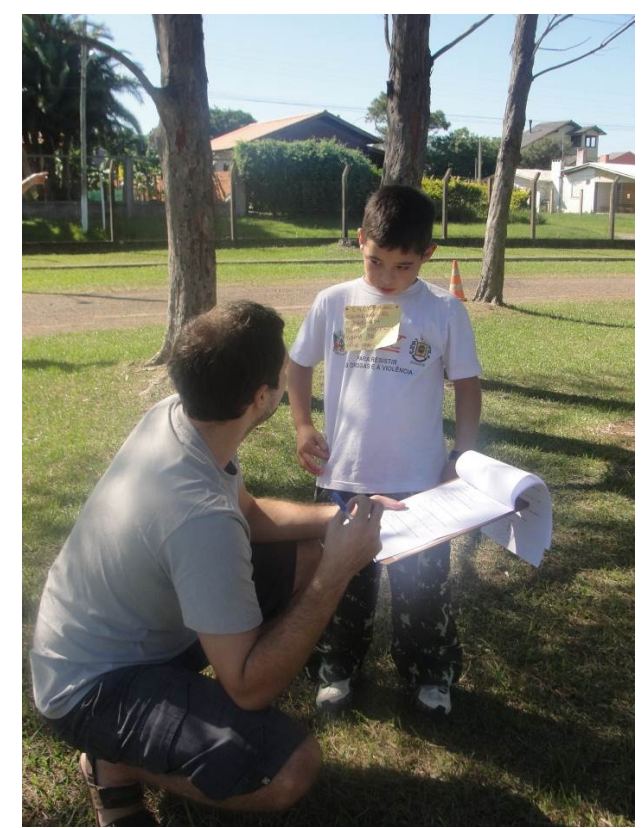

Figura 1: Aplicação do questionário estruturado com os alunos visitantes do Museu de Ciências Naturais do CECLIMAR.

Como forma de padronizar o universo amostral, os questionários aplicados abrangeram $20 \%$ do total de alunos de cada grupo visitante. Como é um método inédito, testes estatísticos foram aplicados com o intuito de ilustrar

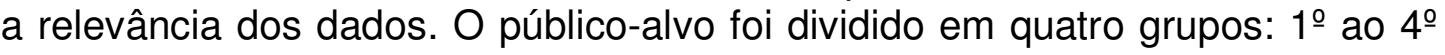
ano (grupo 1); 5ำ ao $9^{\circ}$ ano (grupo 2), ambos do Ensino Fundamental; Ensino Médio (grupo 3); e, por fim, Ensino Superior (grupo 4). Desse modo, o n amostral, é dependente da frequência de visitas ao Museu de Ciências Naturais do CECLIMAR. As diferenças entre grupos pareados foram verificadas aplicando-se o teste pareado de Mann-Whitney e para diferenças entre os quatro grupos de forma geral, aplicou-se o teste de Kruskal-Wallis. Ambas as análises foram desenvolvidas com o software SPSSC (versão 17.0).

O questionário estruturado também possuía cinco imagens, onde 0 entrevistado respondia se a imagem ilustrava um modo de inserção à natureza, segundo seus preceitos intrínsecos. Estabeleceu-se a ordem das imagens em função do objetivo do presente trabalho (Figura 2). A fotografia número um representa um ambiente muito preservado; a imagem quatro, em contrapartida, mostrou a orla de Balneário Camboriú (Santa Catarina), com alto índice de urbanização. A imagem dois apresentou atividades agrícolas, indagando se a agricultura é considerada um modo de natureza já que ela é realizada pelo homem (ação antrópica, Fenker (2007)). A imagem três instiga a intervenção 
do homem na domesticação dos animais e a figura cinco apresenta um campo de dunas da região costeira do RS, sem animais ou plantas evidentes. Nesse caso, nossa intenção foi verificar se paisagens monotípicas da natureza são compreendidas como Natureza.

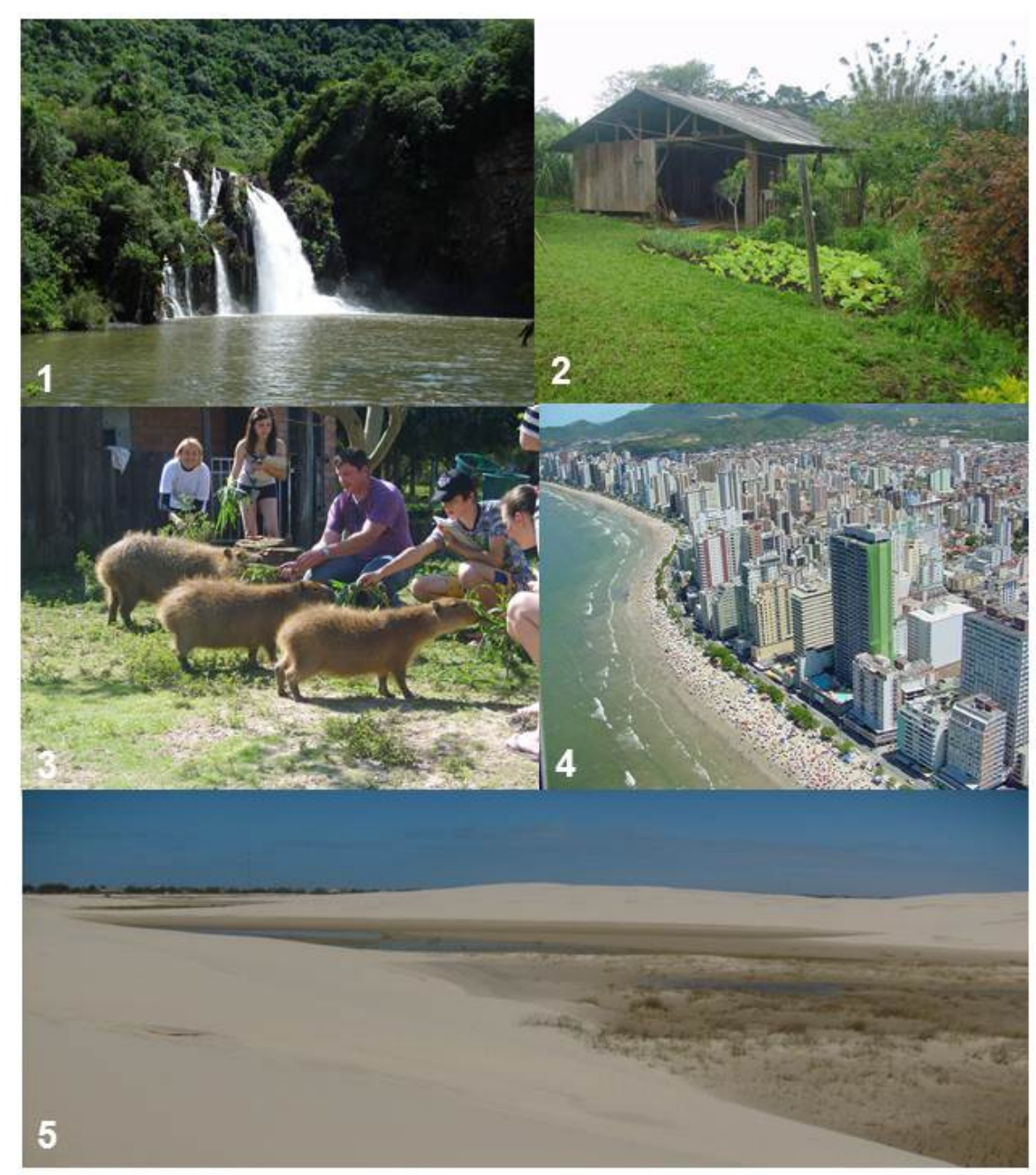

Figura 2 - Fotos utilizadas no questionário em ordem de aplicação.

\section{RESULTADOS E DISCUSSÕES}

No total, foram aplicados 67 questionários, de alunos oriundos de sete cidades do Rio Grande do Sul, sendo a maioria da região metropolitana de Porto Alegre. O grupo com maior representatividade foi o grupo 2 (46,27\%), seguido do grupo 1 (23,88\%), do grupo $4(16,42 \%)$ e do grupo $3(13,43 \%)$. Os grupos 1 e 2 são compostos, na sua totalidade, por alunos oriundos de escola pública. Em contrapartida, o grupo 3 é composto por estudantes de uma única escola particular, enquanto que no Ensino superior, a proporção foi semelhante. Observou-se que na maioria das perguntas, os alunos do grupo 4 apresentaram maior percentagem de respostas "SIM", como mostra a Figura 3, 
corroborando com nossa hipótese inicial. A inexistência de um padrão nas respostas do grupo 1 pode estar relacionada com à idade dos alunos desse grupo. O nível de escolaridade pode ter dificultado a correta compreensão de algumas das perguntas.
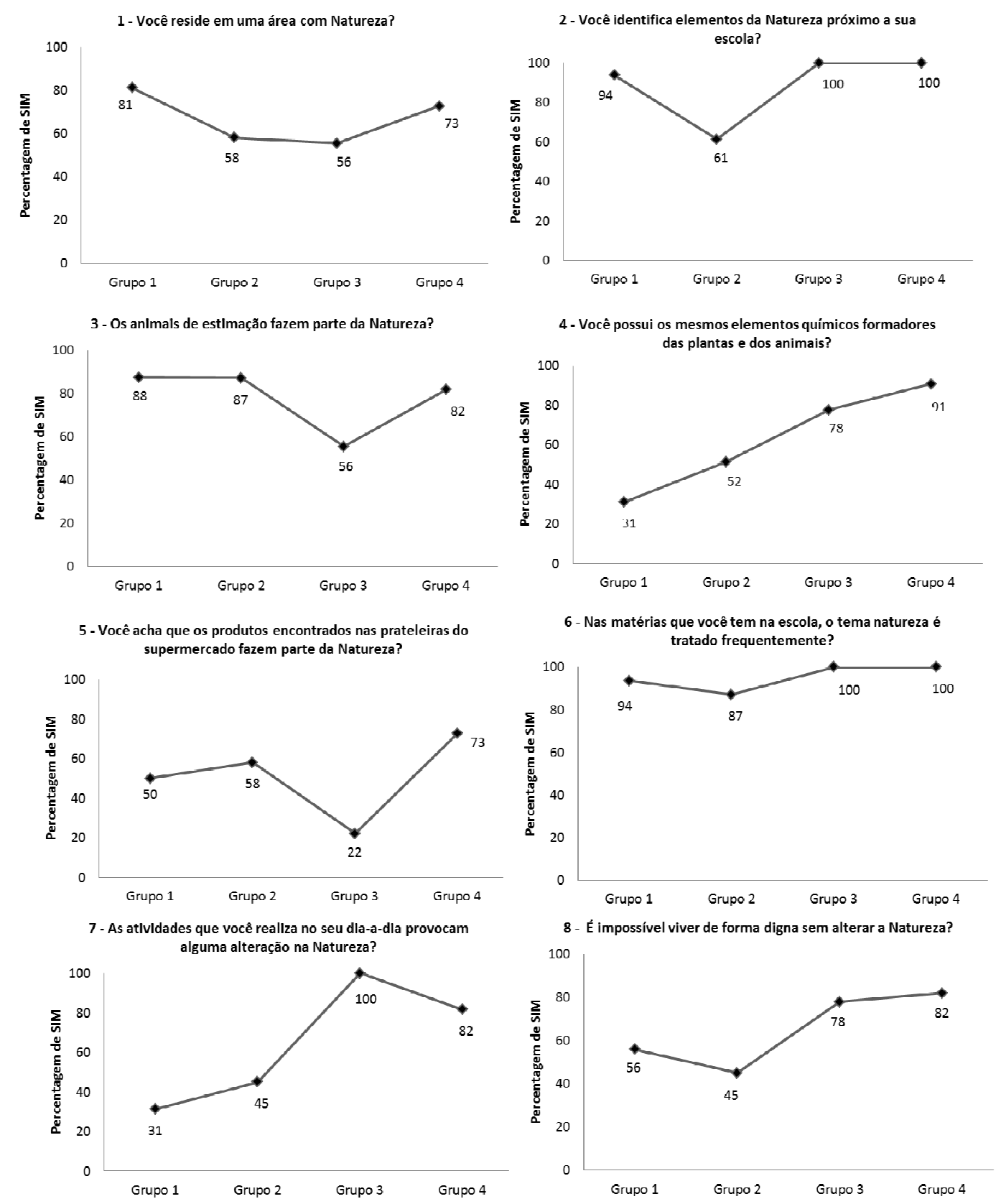

Figura 3 - Percentagem de respostas positivas em relação a cada grupo em cada pergunta.

Revbea, Rio Grande, V. 8, № 2:93-102, 2013. 
A pergunta 4 apresentou um padrão crescente quanto às percentagens de respostas positivas para a pergunta: "Você possui os mesmos elementos químicos formadores das plantas e dos animais?", comprovando que a consideração de inserção na Natureza relaciona-se melhor com os alunos de maior escolaridade.

O grupo 3 apresentou respostas inesperadas nas perguntas 1, 3 e 6 , as quais este grupo obteve a menor percentagem de resposta positiva. A maioria dos alunos do Ensino Médio não consideram os animais de estimação e os produtos presentes nas prateleiras dos supermercados como partes da Natureza, nem identificam elementos da Natureza próximos a suas residências. Não obstante, quando questionados se o tema Natureza é tratado frequentemente na escola e se provocam alguma alteração no meio ambiente, todos os alunos responderam que sim.

O tema Natureza está em alta nos últimos anos, por este motivo as escolas estão tratando deste assunto frequentemente. No entanto, este assunto deve ser tratado desde as séries iniciais para um melhor entendimento e uma maior conscientização com relação às questões ambientais e a relação homem vs. Natureza. As respostas dos alunos demonstram um afastamento da natureza nas séries iniciais, o que influenciaria diretamente nas respostas. Esta é uma especulação, mas também é uma possibilidade. Contudo, esta hipótese pode ser apoiada pelo fato de que os alunos do grupo 1 obtiveram uma percentagem de respostas positivas bem mais elevadas que o grupo 3 nas mesmas três perguntas.

Houve divergências com significância estatística $(p<0,05)$ entre todos os grupos em duas perguntas: "os seres humanos são constituídos dos mesmos elementos que formam as plantas e os animais?"; "nossas atividades rotineiras provocam alguma alteração ao meio ambiente?". Isto significa que a primeira pergunta, possivelmente, foi melhor compreendida pelos grupos que já compreendiam que os elementos químicos que constituem os seres vivos, de forma geral, são homólogos. Na segunda pergunta o mesmo padrão, em relação à questão anterior, foi observado. Provavelmente os mais jovens (grupo 1) ainda não compreendem que qualquer atividade antrópica pode provocar alteração, ainda que o impacto seja mínimo. A baixa faixa etária pode também ter dificultado a compreensão da pergunta pelo grupo 1.

Quanto às fotos, a imagem 4, referente à orla urbanizada do Balneário de Camboriú, foi interpretada como elemento externo à Natureza pela maioria dos entrevistados, dos quatro grupos, sem diferença de nível escolar, idade e tipo de ensino (Figura 4). A imagem 5, mostrando um campo de dunas, também apresentou diferenças entre os grupos $(p<0,05)$. Campos de dunas são paisagens praticamente monotípicas, contrastando com as imagens que normalmente são associadas à Natureza, isto é, imagens utilizadas em diversos meios midiáticos como paisagem típica da natureza. Para as demais imagens, as frequências das respostas foram similares. 


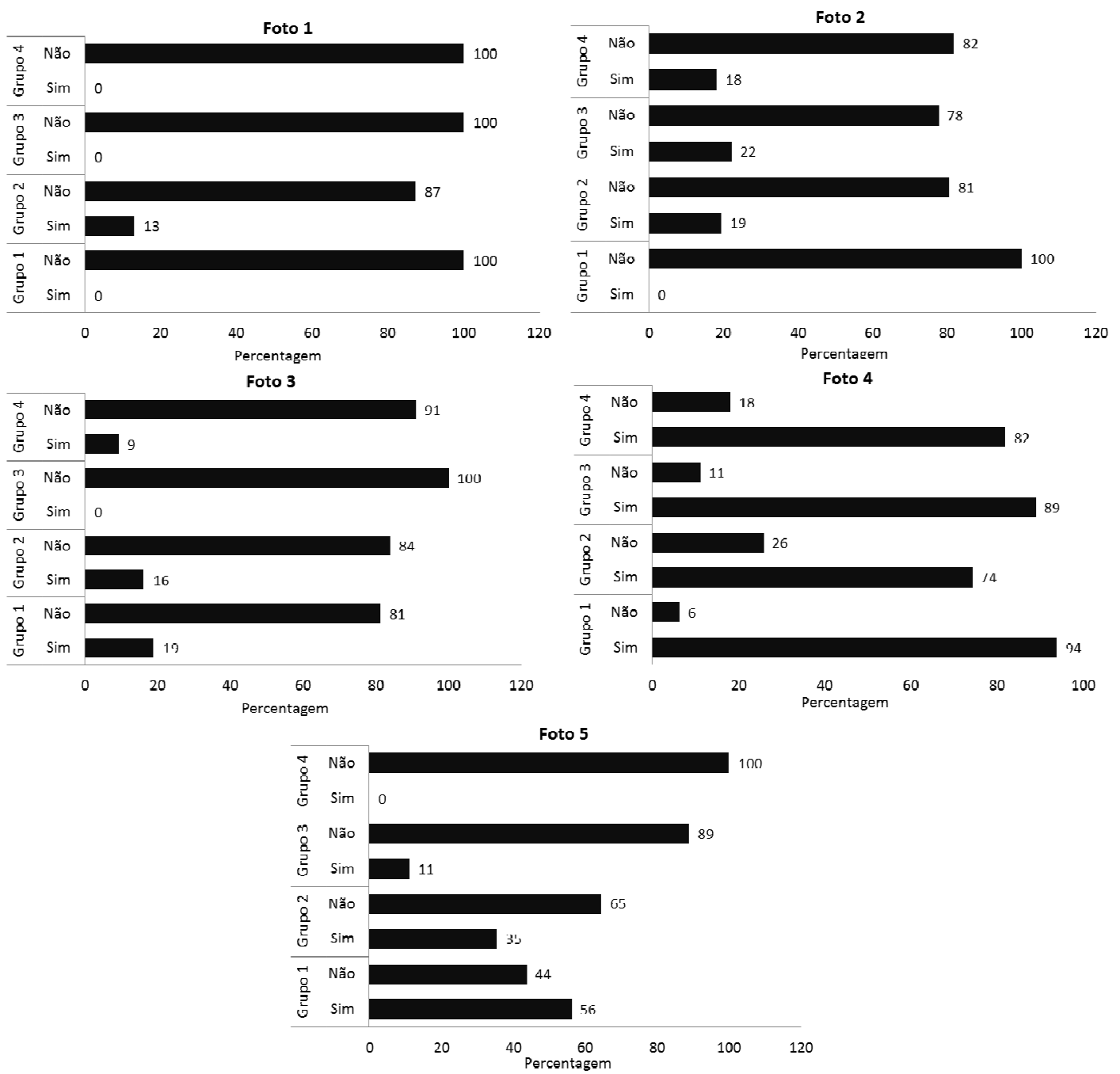

Figura 4 - Frequências de respostas das fotos por grupo entrevistado.

Em relação ao tipo de ensino, público ou privado, houve divergências nas respostas obtidas. No entanto, as diferenças não são significativas estatisticamente. Os alunos do ensino privado pertencem ao ensino médio de uma única escola, enquanto os alunos de escola pública são oriundos do ensino fundamental e superior, de diferentes instituições de ensino, fato que influenciou o resultado. Devido a tais características do público entrevistado, não foi possível estabelecer diferenças na percepção ambiental entre ensino público e privado. Este resultado ilustra um exemplo de limitação do método empregado, pois os grupos não são uniformes e muitas vezes uma abordagem qualitativa poderá ser válida.

O presente trabalho está em consonância com o estudo de Gama e Borges (2009). Durante visitas a uma escola em Uberlândia, Minas Gerais, os autores verificaram que os alunos não se reconhecem como parte do meio ambiente, mas a maioria afirmou colaborar para conservá-lo por ser importante à sobrevivência humana. Além disso, consoante com Figueiró (2011), é errado 
afirmar que a Natureza está em disputa apenas pela apropriação territorial, mas também pela apropriação conceitual e cultural, do que ela significa.

\section{CONCLUSÕES}

O método utilizado foi satisfatório, pois a maioria dos dados mostraramse válidos estatisticamente. No entanto, certos grupos podem ter sido representados por um conjunto homogêneo de dados, como no caso do grupo 3 , todos de escola privada. Parte da hipótese foi confirmada, pois houve aumento da compreensão dos modos de inserção à Natureza em relação ao aumento do nível de ensino, embora a urbanização não seja vista como parte da Natureza por nenhum dos grupos entrevistados. O método empregado ainda carece de mais estudos e de novas abordagens. Este trabalho configura uma primeira amostra de análises a partir de dados de um grupo inicialmente desconhecido amostralmente. Assim, esta nova abordagem pode oferecer um novo método de estudos em instituições que promevem a Educação Ambiental a grupos multiculturais.

\section{REFERÊNCIAS}

BERGMANN, M. Análise da percepção ambiental da população ribeirinha do Rio Santo Cristo e de estudantes e professores de duas escolas públicas, município de Giruá, RS. 104 f.. Dissertação (Mestrado em Ecologia) Programa de Pós-graduação em Ecologia, Instituto de Biociências, Universidade Federal do Rio Grande do Sul, Porto Alegre. 2007.

BRÜGGER, P. Educação ou adestramento ambiental? [S.I]: Letras contemporâneas, 1999.

GAMA, L.U.; BORGES, A.A.S. Educação Ambiental no Ensino Fundamental: a experiência de uma escola municipal de Uberlândia (MG). Revista Brasileira de Educação Ambiental. Rio Grande v. 5, n. 1, 8 p. 2010.

FAGGIONATO, S. Percepção Ambiental. Disponível em: $<$ http://educar.sc.usp.br>. Acessado em 24 de junho de 2011.

FENKER, E. A. Natureza: Fonte de Matéria-Prima para o Homem? Disponível em:<http://www.ambientebrasil.com.br/noticias/index.php3?action=ler\&id=31911>. Acesso em: 28/05/2012.

FIGUEIRÓ, A.S. A Educação Ambiental em tempos de globalização da Natureza. Revista Brasileira de Educação Ambiental. Rio Grande, v. 6, p. 41-47. 2011.

PALMA, I.R. Análise da percepção ambiental como instrumento ao planejamento da educação ambiental. 83 f. Dissertação (Mestrado em Engenharia) - Programa de Pós-graduação em Engenharia de Minas, Metalúrgica e de Materiais, Escola de Engenharia, Universidade Federal do Rio Grande do Sul, Porto Alegre. 2006.

Revbea, Rio Grande, V. 8, № 2:93-102, 2013. 
PELIZZOLI, M. L. Correntes da ética ambiental. Rio de Janeiro: Vozes. 2002. PORTO, M. de F. M. M. Educação Ambiental: conceitos básicos e instrumentos de ação (Manual de Saneamento e Proteção Ambiental para os Municípios). Belo Horizonte: Fundação Estadual do Meio Ambiente, DESA/UFMG. 1996.

RITTER, M.N.; AGOSTINI, V.O.; WOLLMANN, N.; PEREIRA, N.; TRIGO, C. Museu de Ciências Naturais do CECLIMAR/UFRGS: Educação Ambiental para além do Litoral Norte Gaúcho. In: Anais do 10ํ Salão de Extensão da UFRGS. Porto Alegre. 2009.

RODRIGUES, G.S.; FEIJÓ, A.G.S. Ética e ecologia: fundamento para um ecoturismo responsável e eficaz. In: Anais do VIII Congresso de Ecologia do Brasil. Caxambu, MG, 2p. 2007.

VENTURA, V.; SOUSA, I.C.F. Refletindo sobre a relação entre natureza humana, valores capitalistas e a crise ambiental: contribuições para a promoção da Educação Ambiental crítica. Ambiente \& Educação, Rio Grande, vol. 15, n. 1, p. 13-34, 2010. 
ANEXO - Questionário

IDADE SÉRIE LOCAL

ESCOLA: $\square$ PÚBLICA

PARTICULAR

1) Você reside em uma área com Natureza? $\square$ SIM $\square$ NÃO

2) Você identifica elementos da Natureza próximo a sua escola?
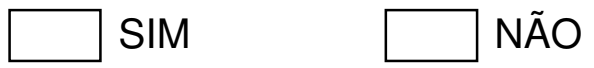

3) Os animais de estimação fazem parte da Natureza?
$\square$ SIM
$\square$ NÃO

4) Você possui os mesmos elementos químicos formadores das plantas e dos animais?
$\square$ SIM
$\square$ NÃO

5) Você acha que os produtos encontrados nas prateleiras do supermercado fazem parte da Natureza?
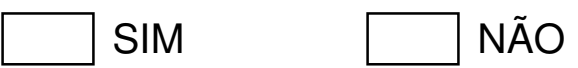

6) Nas matérias que você tem na escola, o tema Natureza é tratado frequentemente?
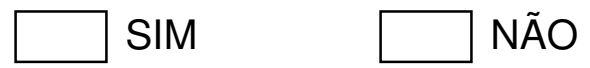

7) As atividades que você realiza no seu dia-a-dia provocam alguma alteração na Natureza?
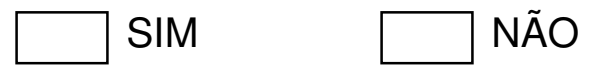

8) É impossível viver de forma digna sem alterar a Natureza?
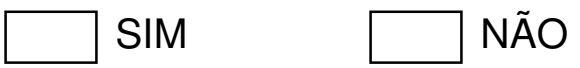

9) Esta foto representa a Natureza? (Veja Figura 2)

Foto 1

Foto 2

Foto 3

Foto 4

Foto 5
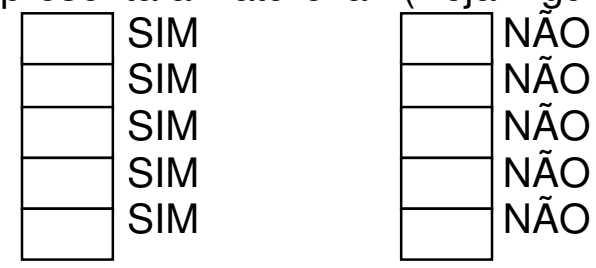

Revbea, Rio Grande, V. 8, № 2:93-102, 2013. 